\title{
Captive Breeding of Anabas testudineus (Climbing Perch) under Semi- artificial Conditions for the Mass Production of Fish Seed for Conservation and Aquaculture
}

\author{
${ }^{1}$ P.A.C.T. Perera, ${ }^{2}$ K.A.H.T. Kodithuwakku, ${ }^{3}$ T.V. Sundarabarathy and ${ }^{2}$ U. Edirisinghe \\ ${ }^{1}$ Post Graduate Institute of Agriculture, University of Peradeniya, Sri Lanka \\ ${ }^{2}$ Department of Animal Science, Faculty of Agriculture, University of Peradeniya, Sri Lanka \\ ${ }^{3}$ Department of Biological Science, Faculty of Applied Sciences, University of Rajarata, Mihintale, Sri Lanka
}

\begin{abstract}
Background: Anabas testudineus is a freshwater perch in tropical and subtropical Asia. Market demand for this fish is high due to favourable qualities in their muscle meat. Nevertheless, availability of this fish in the Sri Lankan market is at a low level due to introduction of exotic species and unavailability of research and development of its aquaculture. Hence, method of mass production of seedlings of this fish has become mandatory for the conservation purposes and to use this fish as a cultured fish in Sri Lankan reservoirs. Aim of study: The objective of this study was to develop a semi-artificial breeding technique for A. testudineus under local conditions. Methods: Matured fish captured from the wild were acclimatized for two weeks. Randomly selected male and female fish were stocked at 1:1 ratio in three different water systems in order to study the possibilities of breeding. Further investigations were carried out by induce their breeding with Salmon GnRHa $\left(\mathrm{Ovaprim}^{\oplus}\right)$. Seven breeding trials were conducted each with five replicates using seven Ovaprim doses (viz., 2, 2.5, 3, 3.5, 4, 4.5 and $5 \mathrm{~mL} \mathrm{~kg}^{-1}$ b.wt. of fish) and administered as a single intramuscular injection for females. Male fish received half of the dose. Hormone treated fish were kept in aerated glass aquaria. Results: It was observed that $A$. testudineus did not breed naturally under captive conditions. Successful ovulation was only obtained with Ovaprim in the group treated with $0.5 \mathrm{~mL} \mathrm{~kg}^{-1}$ b.wt.
\end{abstract}

Key words: GnRHa, intramuscular injection, ovaprim, ovulation

Insight Ecology 2 (2) : 8-14, 2013

\section{INTRODUCTION}

Anabas testudineus (Bloch, 92; Climbing perch) is an anabantid which occurs mainly in lakes, swamps and estuaries ${ }^{1,2}$, sluggish flowing canals, medium to large rivers, flooded fields and stagnant waters ${ }^{3}$ in most tropical and subtropical Asia ${ }^{4,5,6,7,8}$. It is one of the hardiest fish in Sri Lanka's inland waters ${ }^{9}$ and locally known as "Kavaiya". They can thrive in oxygen depleted water bodies using their special accessory air breathing organ which facilitates the utilization of atmospheric air for their respiration ${ }^{10}$. Therefore, well known for their ability to migrate overland from one water body to another ${ }^{9,11,12}$ and these migrations can be observed frequently during the drought in the Dry Zone of Sri Lanka. Anabas testudineus is described as insectivorous ${ }^{13}$ or omnivorous ${ }^{8,9,14}$ by some authors. They are well known due to taste, high nutritive value and recuperative qualities in their muscle meat. It contains high iron and copper which is essential for

Corresponding Author: P.A.C.T. Perera, Post Graduate Institute of Agriculture, University of Peradeniya, Sri Lanka Tel: +9471 8073288 haemoglobin synthesis ${ }^{15}$. Therefore it is mainly given to nursing mothers, children and convalescent people in the rural villages of Sri Lanka.

In Sri Lanka, the exotic species, such as tilapias (Catla catla and Labeo rohita), the Chinese carps (Oreochromis mossambicus and O. niloticus) and the Indian carps (Ctenopharyngodon idella, Hypophthalmichthys molitrix and $C$ yprinus carpio) have so far been the major target species for aquaculture. Such introductions of exotics, water pollution and increasing land use for cropping have already instigated the vulnerability of A. testudineus. Presently, they can only be collected from the lotic and lentic waters where they breed naturally. High price and market demand for this fish persuade fishers to capture them especially from man-made lakes in the dry zone of the country. However, the major constraint in marketing of this species is the non-availability of this fish in daily fish catches. Therefore, the objective of the study is to introduce an enduring system to produce seeds of $A$. testudineus through 
induced breeding as a solution to supply fish fry to inland reservoirs and fish farmers which will ensure conservation of this species as well.

Several successful studies have been carried out to stimulate maturation and ovulation of $A$. testudineus using various hormone preparations such as Ovaprim ${ }^{16}$, Wova-FH ${ }^{17}$, LHRHa combination with a dopamine inhibitor (Motillium ${ }^{18}$ ) and pituitary gland extract ${ }^{19}$. Therefore, Salmon GnRHa (Ovaprim) was used for the present study in order to stimulate breeding of wild-captured $A$. testudineus. It is expected that the information of the present study will also be helpful to develop similar techniques in captive breeding, seed production and propagation of $A$. testudineus.

\section{MATERIALS AND METHODS}

Collection of fish: This study was carried out at the Department of Animal Science (Faculty of Agriculture) of the University of Peradeniya, Sri Lanka. Fish were collected from the river "Malwatu Oya" near Anuradhapura city in the North Central Province one month before the onset of Northeast Monsoon rain (December-February) and kept them in cement tanks alfresco for acclimatization.

Induce breeding under natural water conditions: After one month, three different water systems were arranged using 36 cement tanks (area- $1 \times 1 \mathrm{~m}$; water depth $-30 \mathrm{~cm}$ ) in order to stimulate the spawning of fish without hormonal manipulation. The fist twelve tanks were provided with water flowing system with some aquatic plants. The second set of twelve tanks was provided with water flowing system without aquatic plants. The third set of twelve tanks was provided with stagnant water with some aquatic plants. Bottom of each tank was covered with fine sand and mud up to $5 \mathrm{~cm}$ height. Water was taken by a natural pond located at the Department premises. These tanks were kept for three days to settle silt and mud particles prior to the introduction of fish. Thirty six pairs of matured male and female fish at 1:1 ratio ${ }^{20}$ were randomly selected and transferred to these spawning tanks. Hence, each tank occupied one pair of brooder fish. Body weight of each fish was recorded at the time of transfer using an electronic top-loading balance. Total Dissolved Solids and Conductivity were measured with a multi-parameter (HANNA multiparameter meter, HANNA Instruments, USA, HI 991404-01) and Dissolved Oxygen and temperature were measured with $\mathrm{HACH}$ Sension Waterproof Dissolved Oxygen Meter (HACH-USA, DO6 5020). All the brooders were fed with live feed twice a day and kept undisturbed. They were observed for spawning for two weeks. The water quality parameters in different systems were analysed using one-way ANOVA and the means were compared at 95\% significant level.

Mode of reproduction: Anabas testudineus is bisexual and mature in six months $s^{20}$. Sexual dimorphism is generally observed with the approach of the breeding season. It is also a seasonal breeder with a long period of breeding. Spawning occurs once a year. Spawning season in different localities of India and Bangladesh commence in April and extends to October ${ }^{20}$. However, it has been observed that in Malwatu Oya, female A. testudineus possessed mature eggs from October to April of the year.

Identification of male and female fish: Sexual dimorphism in $A$. testudineus does not distinctively appear $^{21}$. However it is practically possible during the breeding season. Therefore, identification of male and female brooders was done on the basis of some external features (Table 1).

Hormone administration: The use of $\mathrm{GnRH}$ analogues in aquaculture serves several purposes; advancing the spawning season, initiating the process of final oocyte maturation and synchronizing the spawning of brood-stock ${ }^{22}$. Under captive conditions, fish often develop mature gonads and gametes but fail to undergo the process of final oocyte maturation and spawning, due to an insufficient surge of $\mathrm{GtH}$ from the pituitary. Thus, females may develop vitellogenic oocytes; yet remain incapable of ovulating. Captive stocks which may have not fully prepared for spawning can be induced to ovulate artificially by hormonal injections ${ }^{20}$. Ovaprim (Syndel International Inc., Canada) is a combination of SGnRHa and dopamine antagonist ${ }^{23,24}$. It is one of the most widely acceptable and readily available synthetic hormones because it has been found to be very effective ${ }^{25,26}$. In order to measure the hormone accurately, a stock solution was prepared using the original Salmon GnRHa (Ovaprim).

Table 1: External features used to identify male and female brood fish of A. testudineus

\begin{tabular}{|c|c|}
\hline Female & Male \\
\hline $\begin{array}{l}\text { Swollen abdomen/girth is distended } \\
\text { with the develop ovary" }\end{array}$ & Slender in appearance \\
\hline $\begin{array}{l}\text { Distance between the base of the pectoral fins } \\
\text { is greater than the length of the isthmus }{ }^{\# \#}\end{array}$ & Lesser \\
\hline $\begin{array}{l}\text { Eject yellowish eggs following gentle } \\
\text { pressure on the abdomen }\end{array}$ & $\begin{array}{l}\text { Eject milt when light } \\
\text { pressure is applied on the } \\
\text { abdomen }\end{array}$ \\
\hline Body coloured and slightly brighter & Body coloured and darker \\
\hline $\begin{array}{l}\text { In the breeding season female exhibits } \\
\text { a prominent bulge at the vent } \\
\text { resembling genital papilla }{ }^{\# \# \#}\end{array}$ & This structure is absent \\
\hline
\end{tabular}


One part of hormone was dissolved in nine parts of saline $\mathrm{NaCl}(0.7 \%)$ and frozen at $-20^{\circ} \mathrm{C}$ until use. One millilitre of stock solution contained $0.10 \mathrm{~mL}$ of original Salmon GnRHa. Seven different doses (Table 2) of Salmon GnRHa (Ovaprim) were administered intramuscularly according to their body weight into the dorsolateral region of each fish in a single dose as described by Haniffa et al. ${ }^{27}$. The females were treated with full doses of GnRHa (Ovaprim) and male fish were treated with half of the dose at the same time. Thirty-five pairs of fish were carefully transferred to $0.75 \times 0.30 \times 0.30 \mathrm{~m}$ size indoor glass aquaria with sufficient aeration immediately after the hormonal administration. Hence, each tank was occupied by a pair of brood fish. Each dose was tested using five pairs of brooders. Response of each pair of brooder to each dose of GnRHa (Ovaprim) was observed (Table 2).

Fertilization and hatching: Eggs released by female fish were allowed to fertilize naturally by the milt of the

Table 2: Different doses and volumes of Ovaprim administered to brood fish of $A$. testudineus

\begin{tabular}{llccc}
\hline \multicolumn{5}{l}{ Ovaprim dosage } \\
$\begin{array}{l}\text { Experimental } \\
\text { group No. }\end{array}$ & $\begin{array}{l}\text { Female fish } \\
\left(\mathrm{mL} \mathrm{kg}^{-1}\right)\end{array}$ & $\begin{array}{l}\text { Stock solution } \\
(\mu \mathrm{L})\end{array}$ & $\begin{array}{l}\text { Male fish } \\
\left(\mathrm{mL} \mathrm{kg}^{-1}\right)\end{array}$ & $\begin{array}{l}\text { Stock solution } \\
(\mu \mathrm{L})\end{array}$ \\
\hline 1 & 0.20 & 200 & 0.100 & 100 \\
2 & 0.25 & 250 & 0.125 & 125 \\
3 & 0.30 & 300 & 0.150 & 150 \\
4 & 0.35 & 350 & 0.175 & 175 \\
5 & 0.40 & 400 & 0.200 & 200 \\
6 & 0.45 & 450 & 0.225 & 225 \\
7 & 0.50 & 500 & 0.250 & 250 \\
\hline
\end{tabular}

male in the same spawning tank. Once complete ovulation was observed, the time taken for ovulation was noted, the male and female fish were removed and excreta if any, was removed by careful siphoning. Fertilized eggs were incubated at room temperature with continuous aeration. The latency period (h), incubation period (h), fertilization rate (\%), hatching rate (\%), water temperature $\left({ }^{\circ} \mathrm{C}\right.$ ) and $\mathrm{pH}$ were determined (Table 4).

\section{RESULTS}

Breeding under natural conditions: Though three different natural water systems were provided A. testudineus did not ovulate under captive conditions. However, each female was found to pair with a male. Nest building characteristic was not observed. Males were more active and aggressive (Table 3) .

Ovaries: The ovary of $A$. testudineus is a bilobed structure (Fig. 1) lying just ventral to the air bladder and is attached to the body cavity by a thin membrane. The left ovary is slightly larger in length than that of the right. The well matured ovary is granular in appearance and yellow in colour.

Semi-artificial breeding of $A$. testudineus: All the fish in thirty five experimental units survived after the hormone administration. Induced females were found to ovulate $12-15 \mathrm{~h}$ after hormonal administration. It was observed that the male Climbing perch rubbed its body with that of the female and released mint and the eggs

Table 3: Water quality parameters in the three systems

\begin{tabular}{lccc}
\hline Parameter & Flowing water with aquatic plants & Flowing water without aquatic plants & Stagnant water with aquatic plants \\
\hline Total dissolved solids $\left(\mathrm{mg} \mathrm{L}^{-1}\right)$ & $121.00 \pm 16.2^{\mathrm{a}}$ & $86.00 \pm 8.9^{\mathrm{b}}$ & $77.00 \pm 5.6^{\mathrm{b}}$ \\
Dissolved oxygen $\left(\mathrm{mg} \mathrm{L}^{-1}\right)$ & $8.60 \pm 1.2^{\mathrm{a}}$ & $7.90 \pm 1.5^{\mathrm{a}}$ & $7.10 \pm 2.2^{\mathrm{a}}$ \\
Conductivity $\left(\mu \mathrm{s} \mathrm{cm}^{-1}\right)$ & $242.00 \pm 29.3^{\mathrm{a}}$ & $120.60 \pm 5.1^{\mathrm{b}}$ & $107.40 \pm 8.7^{\mathrm{b}}$ \\
$\mathrm{pH}$ & $8.23 \pm 1.5^{\mathrm{a}}$ & $8.31 \pm 1.3^{\mathrm{a}}$ & $8.09 \pm 1.1^{\mathrm{a}}$ \\
Temperature $\left({ }^{\circ} \mathrm{C}\right)$ & $24.50 \pm 0.6^{\mathrm{a}}$ & $24.70 \pm 1.0^{\mathrm{a}}$ & $25.60 \pm 1.2^{\mathrm{a}}$ \\
\hline
\end{tabular}

Values within rows having differet superscripts are significantly different $(\mathrm{p}<0.05)$, Values are expressed as Mean \pm SD

Table 4: Results of semi-artificial breeding experiment of Anabas testudineus treated with different doses of Ovaprim (GnRHa) hormone

\begin{tabular}{|c|c|c|c|c|c|c|c|}
\hline \multirow[b]{2}{*}{ Parameters } & \multicolumn{7}{|c|}{ Experiment No. } \\
\hline & 1 & 2 & 3 & 4 & 5 & 6 & 7 \\
\hline Ovaprim dosage ( $\left.\mathrm{mL} \mathrm{kg}^{-1}\right)$ b.wt. & 0.2 & 0.25 & 0.3 & 0.35 & 0.4 & 0.45 & 0.5 \\
\hline \multicolumn{8}{|l|}{ Weight of fish (g) } \\
\hline Female & $55.9 \pm 3.3$ & $50.9 \pm 3.2$ & $50.5 \pm 2.5$ & $49.5 \pm 3.3$ & $53.6 \pm 1.6$ & $50.9 \pm 1.0$ & $51.3 \pm 2.5$ \\
\hline Male & $56.2 \pm 1.9$ & $51.7 \pm 6.4$ & $53.6 \pm 4.0$ & $56.1 \pm 2.0$ & $52.0 \pm 5.9$ & $53.4 \pm 3.6$ & $56.2 \pm 1.9$ \\
\hline \multicolumn{8}{|l|}{ Length of fish $(\mathrm{cm})$} \\
\hline Female & $15.0 \pm 0.5$ & $14.6 \pm 0.3$ & $15.1 \pm 0.3$ & $15.1 \pm 0.4$ & $14.9 \pm 0.3$ & $15.2 \pm 0.3$ & $15.0 \pm 0.4$ \\
\hline Male & $15.4 \pm 0.1$ & $15.0 \pm 0.4$ & $15.5 \pm 0.3$ & $15.0 \pm 0.5$ & $15.4 \pm 0.4$ & $14.9 \pm 0.4$ & $15.2 \pm 0.4$ \\
\hline Latency period (h) & $\mathrm{Nil}$ & Nil & Nil & Nil & $\mathrm{Nil}$ & $\mathrm{Nil}$ & $14.6 \pm 0.15$ \\
\hline Fecundity & $\mathrm{Nil}$ & $\mathrm{Nil}$ & $\mathrm{Nil}$ & $\mathrm{Nil}$ & $\mathrm{Nil}$ & Nil & $40220 \pm 7676$ \\
\hline Fertilization (\%) & $\mathrm{Nil}$ & $\mathrm{Nil}$ & Nil & $\mathrm{Nil}$ & $\mathrm{Nil}$ & Nil & $93.0 \pm 10.32$ \\
\hline Hatching (\%) & $\mathrm{Nil}$ & $\mathrm{Nil}$ & $\mathrm{Nil}$ & $\mathrm{Nil}$ & $\mathrm{Nil}$ & Nil & $87.0 \pm 3.9$ \\
\hline $\mathrm{pH}$ & $8.13 \pm 0.1$ & $8.30 \pm 0.2$ & $8.33 \pm 0.3$ & $8.13 \pm 0.2$ & $7.90 \pm 0.2$ & $8.18 \pm 0.2$ & $8.3 \pm 0.2$ \\
\hline Temperature $\left({ }^{\circ} \mathrm{C}\right)$ & $24.5 \pm 0.4$ & $24.9 \pm 0.2$ & $23.7 \pm 0.7$ & $24.6 \pm 1.4$ & $24.6 \pm 0.8$ & $24.5 \pm 1.1$ & $24.7 \pm 1.2$ \\
\hline Remarks & Not spawned & Not spawned & Not spawned & Not spawned & Not spawned & Not spawned & Spawned \\
\hline
\end{tabular}

Values are expressed as Mean \pm SD 

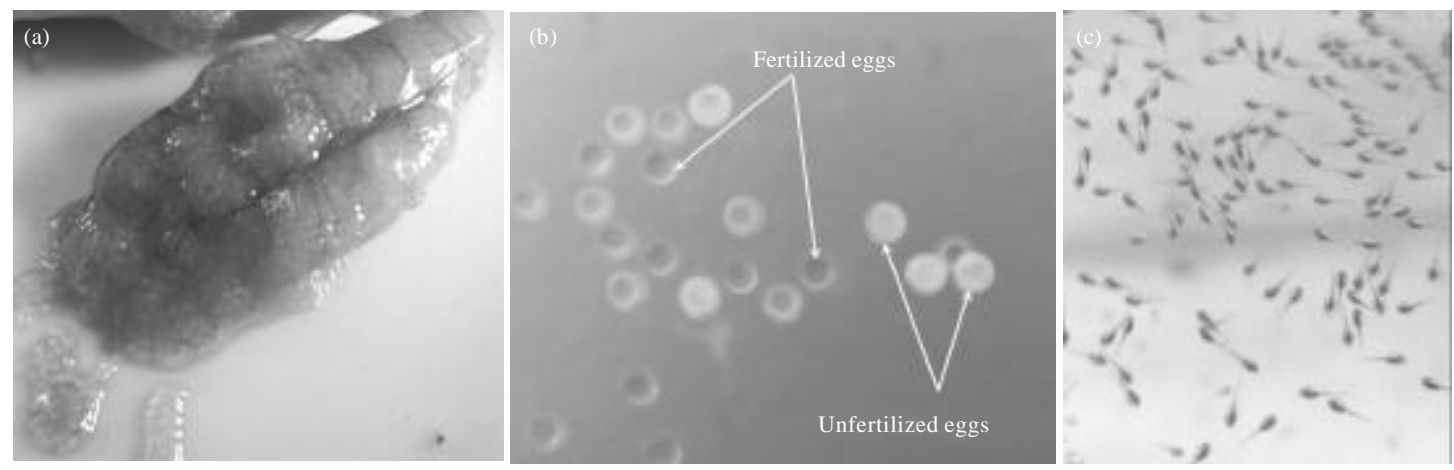

Fig. 1(a-c): (a) Matured ovary, (b) Released eggs after fertilization and (c) Newly hatched larvae of A.testudineus

were fertilized externally. Table 4 indicates the average body weight, dose of Ovaprim, latency period, number of eggs spawned, fertilization and hatching rates.

Ova: Eggs were visible to the naked eyes. Fertilized floating eggs were translucent and non-adhesive whereas unfertilized eggs gave an opaque appearance (Fig. 1).

\section{DISCUSSION}

Fish breed naturally in their inhabitant waters once they receive the environmental cues above the respective threshold value. Until all the environmental cues are satisfied, they are physiologically not ready for spawning. Pethiyagoda ${ }^{9}$, states that $A$. testudineus breed prolifically with the onset of monsoon rains in their natural environments. Failure to spawn in the three different systems (flowing water with aquatic plants, flowing water without aquatic plants and stagnant water with aquatic plants) has left uncertainty of their breeding habits. However, this indicates that flowing water, aquatic plants, mud bottom and aeration of water (as given in this experiment) are not sufficient to induce breeding of A. testudineus. The absence of natural breeding infers that there are some other unidentified conditions that affect natural breeding of this fish. The other factors such as flow rate and water quality may also have contributed to the induction of spawning behaviour. Successful spawning in majority of fishes has been induced on cloudy and rainy days, especially after heavy showers ${ }^{28}$. However, during the present experiment, these environmental variables were not considered.

The hormonal signals that initiate ovulation are naturally induced by specific environmental cues. Mature females of $A$. testudineus having stage IV ova were always used to ovulate by using hormones. Fish which were not successful in natural breeding under stimulated water conditions were subjected to different doses of Ovaprim in glass aquaria inside the laboratory. Similar environmental conditions were supplied for all the fish (Table 4). Patowary and Dutta ${ }^{29}$ have observed low temperatures of about $28^{\circ} \mathrm{C}$ and darkness are important factors for spawning of $A$. testudineus. However, complete darkness was not provided in this experiment. Nevertheless, an undisturbed, quiet environment was guaranteed. Moitra et al..$^{19}$ recommended an optimum ambient temperature of $28.6^{\circ} \mathrm{C}$ for breeding under laboratory conditions. Morioka et al. ${ }^{18}$ states that in the region where the climbing perch occurs, the reproductive season is considered as the pre-rainy, the rainy and the post-rainy seasons when the water temperature is relatively higher $\left(>25^{\circ} \mathrm{C}\right)$. Nevertheless, Morioka has also observed the presence of sexually well mature females when the water temperature was around $18-21^{\circ} \mathrm{C}$ and using these broodstock, fertilized eggs were successfully obtained by semi-artificial propagation. However, present study has demonstrated $23.7 \pm 0.7$ to $24.7 \pm 1.21$ mean temperatures in experimental tanks. The other factors such as suitable water $\mathrm{pH}$ and Dissolved Oxygen levels may also have contributed to the induction of ovulation of $A$. testudineus.

The present study also demonstrated that A. testudineus can be successfully induced to produce sperms and ova using an intramuscular injection of Ovaprim (sGnRHa). Stripping of the male fish was not carried out and eggs were allowed to fertilize naturally. Therefore, one can practice this method even at the farm level with limited facilities and knowledge. However, the dosage of Ovaprim required to successfully ovulate was $0.5 \mathrm{~mL} \mathrm{~kg}{ }^{-1}$. Patowary and Dutta ${ }^{29}$ have observed spawners of $A$. testudineus bred 10 to $12 \mathrm{~h}$ after the Ovaprim injection at $2 \mathrm{~mL} \mathrm{~kg}^{-1}$ b.wt. Nevertheless, for complete spawning it has taken $14.63 \pm 0.15 \mathrm{~h}$ in the present study. Jacob ${ }^{20}$ states that, Ovaprim diluted in distilled water or $0.6 \%$ saline at the recommended dose 
of $0.5 \mathrm{~mL} \mathrm{~kg} \mathrm{k}^{-1}$ b.wt. was ineffective in inducing successful ovulation of $A$. testudineus. However, it was revealed by the present study that Anabas did not ovulate at Ovaprim levels below $0.5 \mathrm{~mL} \mathrm{~kg}{ }^{-1}$. Therefore, the minimum dose of Ovaprim required to induce ovulation of $A$. testudineus is $0.5 \mathrm{~mL} \mathrm{~kg}^{-1}$.

In the present study, mean number of eggs (40 $220 \pm 7676$ ) released by a female having a mean length of $15.0 \pm 0.4 \mathrm{~cm}$ and mean weight of $51.3 \pm 2.5 \mathrm{~g}$ indicates high fecundity. Marimuthu et al. ${ }^{30}$ recorded fecundity ranging from 3120 to 84690 with a size range of $12.4-19.2 \mathrm{~cm}(16.13 \pm 0.249 \mathrm{~cm})$ in total length and with $33.2-137.1 \mathrm{~g}$ in total body weight. Khan and Mukhopadhyay ${ }^{31}$ has observed fecundity ranging from 10002 to 36477 in size range of $99-166 \mathrm{~mm}$. However, Banerjee and Prasad ${ }^{32}$ reported a fecundity of 4588 to 34 993 in size range of $73-182 \mathrm{~mm}$. Zalina et al. ${ }^{8}$ has observed mean fecundity ranging from $2785 \pm 411$ to $30499 \pm 7935$ in size range of $56.1 \pm 4.4 \mathrm{~g}$ after treat with 2, 20 and $200 \mu \mathrm{g}$ $\mathrm{kg}^{-1}$ b.wt. of LHRHa hormone. Jacob ${ }^{20}$ observed $A$. testudineus induced with Ovaprim doses, 1-3 mL and 3-6 $\mathrm{mL} \mathrm{kg}{ }^{-1}$ b.wt., has resulted 9804 and 8792 eggs, respectively. Some of the identified fecundities are more or less deviate from the values observed in the present study. Nevertheless, in general, it indicates a comparatively higher fecundity in $A$. testudineus.

Fertilization was higher than $90 \%$ and the fertilized eggs had hatched within $15 \mathrm{~h}$ after spawning. Jacob ${ }^{20}$ has observed $95.0 \pm 5.0$ and $93.31 \pm 5.0$ mean fertilization rates after injecting Ovaprim doses, $1-3 \mathrm{~mL}$ and $3-6 \mathrm{~mL} \mathrm{~kg}{ }^{-1}$ b.wt. respectively. Zalina et al. ${ }^{8}$ has observed $93.9 \pm 3.0-$ $98.4 \pm 1.2 \%$ fertilization rates when treated with 2,20 and $200 \mu \mathrm{g} \mathrm{kg}^{-1}$ b.wt. of LHRHa hormone. Nevertheless, the fertilization rates observed in the present study (Table 4) is slightly less than the vales observed in the above studies. However, reduced fertilization rates were not attributed to dose or treatment, but rather time to ovulation after initial injection ${ }^{20}$. It was concluded that eggs induced to spawn early in the season had insufficient time to resume meiotic maturation before being ovulated and therefore were incapable of being fertilized.

$\mathrm{Jacob}^{20}$ has observed hatching percentage of

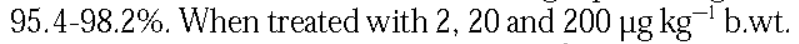
of LHRHa hormone, Zalina et al ${ }^{8}$ has observed $65.33 \pm 2.69,59.61 \pm 2.18$ and $56.52 \pm 35 \%$ hatching rates respectively. Sarkar et al. ${ }^{17}$ reported a hatching rate of $90.5 \pm 3.65^{33}, 68.57$ to $73.11^{18}$ and $100 \%$ hatching. The mean hatching rate $(86.97 \pm 3.88 \%)$ observed in the present study is not much deviated from ${ }^{17,20}$. Nevertheless, the hatching rates are better than that of Zalina et al $l^{8}$. Very high hatching percentages recorded by Morioka et al. ${ }^{18}$ might be related to comparatively higher temperature range $\left(27-30^{\circ} \mathrm{C}\right)$ observed during the period of the experiment. The temperature observed in the present study was considerably lower (Table 4) during the experiment. As temperature is considered one of the main environmental factors ${ }^{34}$ influencing hatching percentage and survival of embryo and larvae ${ }^{35}$. Therefore, it can be the reason for not having very high hatching rate in the present study as observed by ${ }^{18,20}$. However, the success of induced spawning depends on a number of factors, which in most of the fishes are not clearly understood.

\section{CONCLUSION}

The present study shows that $A$. testudineus does not breed naturally under captive conditions provided. Their requirements for natural breeding are more complicated and yet to be identified. The attempt on induced breeding however was found effective when Ovaprim (sGnRHa) was injected as a single dose for females $\left(0.5 \mathrm{~mL} \mathrm{~kg}^{-1}\right.$ b.wt.) and half dose for males. Ovaprim administration produced high rates of ovulation, fertilization and hatching of normal larvae of $A$. testudineus and breeding was semi-artificial. Stripping of the male fish is not necessary.

In Sri Lanka, most of the native fish species are currently not well utilized for aquaculture. Nevertheless, seeds of A. testudineus can be produced semi-artificially at the farm level. The inclusion of this species in Sri Lankan aquaculture can change the current aquaculture systems which depend excessively on exotic fish species.

\section{ACKNOWLEDGMENTS}

Authors would like to express their sincere gratitude to the Chairperson of the Board of Study of Animal Science, Staff of the Department of Animal Science, Faculty of Agriculture, University of Peradeniya for providing the database access and infrastructure facilities without which this study would not have been possible.

\section{REFERENCES}

1. Menon, A.G.K., 1999. Check list-fresh water fishes of India. Records of Zoological Survey of India, Miscellaneous Publication, Occasional Paper No. 175: $1-366$.

2. Vidthayanon, C., 2002. Peat Swamp Fishes of Thailand. Office of Environmental Policy and Planning, Bangkok, Thailand, pages: 136.

3. Taki, Y., 1978. An analytical study of the fish fauna of the Mekong basin as a biological production system in nature. Research Institute of Evolutionary Biology, Special Publications No. 1, Tokyo, Japan, pp: 77.

4. Rainboth, W.J., 1996. Fishes of the Cambodian Mekong: FAO Species Identification Field Guide for Fishery Purposes. FAO, Rome. 
5. Wang, T.Y., C.S. Tzeng and S.C. Shen, 1999. Conservation and phylogeography of Taiwan paradise fish, Macropodus opercularis Linnaeus. Acta Zool. Taiwan., 10: 121-134.

6. Kottelat, M., 2001. Fishes of Laos. WHT Publications, Colombo, Sri Lanka, ISBN-13: 9789559114253, Pages: 198.

7. Tan, H.H. and K.K.P. Lim, 2004. Inland fishes from the Anambas and Natuna Islands, South China Sea, with description of a new species of Betta (Teleostei:Osphronemidae). Raffles Bull. Zool. Suppl., 11: 107-115.

8. Zalina, I., C.R. Saad, A. Christianus and S.A. Harmin, 2012. Induced breeding and embryonic development of climbing perch (Anabas testudineus, Bloch). J. Fish. Aquat. Sci., 7: 291-306.

9. Pethiyagoda, R., 1991. Freshwater Fishes of Sri Lanka. The Wildlife Heritage Trust of Sri Lanka, Colombo, pp: 258-259.

10. Graham, J.B., 1997. Air Breathing Fishes: Evolution, Diversity and Adaptation. Academic Press, San Diego, ISBN: 9780122948602, Pages: 299.

11. Davenport, J. and A.K.M. Abdul Matin, 1990. Terrestrial locomotion in the climbing perch Anabas testudineus (Bloch) (Anabantidea, Pisces). J. Fish Biol., 37: 175-184.

12. Sakurai, A., Y. Sakamoto and F. Mori, 1993. Aquarium Fish of the World: The Comprehensive Guide to 650 Species. Chronicle Books, San Francisco, California, ISBN-13: 978-0811802697, Pages: 296.

13. Yakupitiyage, A., J. Bundit and H. Guhman, 1998. Culture of Climbing perch (Anabas testudineus). A Review. AIT AQUA OUTREACH, Working Paper, New Series No.T-8.

14. Riehl, R. and H.A. Baensch, 1991. Aquarium Atlas. Mergus, Melle, Germany, Pages: 992.

15. Sarma, K., A.K. Pal, S. Ayyappan, T. Das, S.M. Manush, D. Debnath and K. Baruah, 2010. Acclimation of Anabas testudineus (Bloch) to three test temperatures influences thermal tolerance and oxygen consumption. Fish. Physiol. Biochem., 36: 85-90.

16. Bhattacharyya, M. and S. Homechaudhuri, 2009. Assessment of captive breeding of Anabas testudineus with the synthetic hormone, Ovaprim. Proc. Zool. Soc., 62: 23-27.

17. Sarkar, U.K., P.K. Deepak, D. Kapoor, R.S. Negi, S.K. Paul and S. Singh, 2005. Captive breeding of climbing perch Anabas testudineus (Bloch, 1792) with Wova-FH for conservation and aquaculture. Aquacult. Res., 36: 941-945.
18. Morioka, S., S. Ito, S. Kitamura and B. Vongvichith, 2009. Growth and morphological development of laboratory-reared larval and juvenile climbing perch Anabas testudineus. Ichthyol. Res., 56: 162-171.

19. Moitra, A., K.T. Ghosh, A. Pandey and J.S.D. Munshi, 1987. Scanning electron microscopy of the post-embryonic stages of the climbing perch, Anabas testudineus. Jpn. J. Ichthyol., 34: 53-58.

20. Jacob, P.K., 2005. Studies on some aspects of reproduction of female anabas testudineus (Bloch). Ph.D. Thesis, Department of Marine Biology, Faculty of Marine Sciences, Cochin University of Science and Technology, Cochin, India.

21. Morioka, S., S. Ito, S. Kitamura and B. Vongvichith, 2009. Technical report and manual of seed production of the climbing perch Anabas testudineus. JIRCAS Working Report No. 61.

22. Crim, L.W. and S. Bettles, 1997. Use of GnRH Analogues in Fish Culture. In: Endocrinology and Reproduction: Recent Advances in Marine Biotechnology, Volume 1, Fingerman, M., R. Nagabhushanam and M.F. Thompson (Eds.). Oxford and IBH Publishing, New Delhi, India, pp: 369-382.

23. Sahoo, S.K., S.S. Giri and S. Chandra, 2008. Induced spawning of Clarias batrachus (Linn): Effect of Ovaprim doses and latency periods on the weight of stripped eggs and ovary. Asian Fish. Sci., 21: 333-338.

24. Kahkesh, F.B., M.Y. Feshalami, F. Amiri and M. Nickpey, 2010. Effect of ovaprim, ovatide, HCG, LHRH-A2, LHRHA2 + CPE and carp pituitary in benni (Barbus sharpeyi) artificial breeding. Global Vet., 5: 209-214.

25. Olubiyi, O.A., O.A. Ayinia, O.A. Ayinia and A.A. Adeyemo, 2005. The effects of various doses of Ovaprim on reproductive performance of the African catfish Clarias gariepinus (Burchell) and Heterobranchus longifilis (Valenciennes). Afr. J. Applied Zool. Environ. Biol., 7: 101-105.

26. Nwokoye, C.O., L.A. Nwuba and J.E. Eyo, 2007. Induced propagation of African clariid catfish, Heterobranchus bidorsalis (Geoffrey St Hillarie, 1809) using synthetic and homoplastic hormones. Afr. J. Biotechnol., 6: 2687-2693.

27. Haniffa, M.A., J.S. Mohamed and T.M. Rose, 1996. Induction of ovulation in Channa stariatus (Bloch) by SGnRH. Fishing Chimes, 16: 23-24.

28. Chaudhury, H., 1969. Techniques of hypophysation of Indian carps. FAO/UNDP Regional Seminar on Induced Breeding of Cultivated Fishes. Cal. Bom. July 15-Aug 18. Delhi. 
29. Patowary, R.K. and A. Dutta, 2012. Breeding performances of Anabas testudineus (Bloch) in specially designed cemented tanks. Asian J. Exp. Biol. Sci., 3: 762-766.

30. Marimuthu, K., J. Arumugam, D. Sandragasan and R. Jegathambigai, 2009. Studies on the fecundity of native fish climbing perch (Anabas testudineus, Bloch) in Malaysia. Am. Eur. J. Sustainable Agric., 3: $266-274$.

31. Khan, H.A. and S.K. Mukhopadhyay, 1975. Production of stocking material of some airbreathing fishes by hypophysation. J. Inland Fish Soc. India, 7: 156-161.

32. Banerjee, S.R. and D. Prasad, 1974. Observations on reproduction and survival of Anabas testudineus (Bloch) in Bihar region. J. Inland Fish. Soc., 6: 6-17.
33. Bhattacharjee, I., G. Aditya and G. Chandra, 2009. Laboratory and field assessment of the potential of larvivorous, air-breathing fishes as predators of culicine mosquitoes. Biol. Control, 49: 126-133.

34. Gadomski, D.M. and S.M. Caddell, 1991. Effects of temperature on early life history stages of California halibut, Paralichthys californicus. Fish. Bull., 89: 567-576.

35. Das, T., A.K. Pal, S.K. Chakraborty, S.M. Manush, R.S. Dalvi, K. Sarma and S.C. Mukherjee, 2006. Thermal dependence of embryonic development and hatching rate in Labeo rohita (Hamilton, 1822). Aquaculture, 255: 536-541. 